\title{
SESIÓN NECROLÓGICA EN MEMORIA DEL PROF. JOSÉ MARÍA GIL VERNET
}

\author{
Arturo Fernández-Cruz Pérez \\ Académico de Número de la Real Academia Nacional de Medicina de España - Medicina Social \\ Catedrático Emérito de Medicina. Universidad Complutense. Hospital Clínico de San Carlos
}

Excmo. Sr. Presidente, Excmo. Sr. Secretario,

\section{Excmos. Académicos}

Frente a una epidemia que tan furiosamente se extiende, quiero compartir con vosotros el profundo dolor de tener que asumir que Madrid está a la cabeza de contagios y muertes por la Covid-19 en Europa.

Me parte el alma saber la cantidad de muertes que esto ha generado y quiero rendir tributo, antes de empezar mi disertación, a los familiares de estos héroes que han perdido su vida en esta batalla desigual. Deseo además expresar mi más sincero afecto y empatía al personal sanitario que ha luchado y lucha por combatir esta pandemia que nos azota y que están en el camino de doblegarla.

Mi objetivo hoy aquí, señoras y señores académicos es recordar al maestro Gil-Vernet Vila. Como es de esperar en estos actos protocolarios debo realizar un "portrait" es decir un retrato dentro del contexto de su vida profesional y académica

Con su permiso me tomaré la licencia de llevarles a compartir conmigo el concepto de "saga" que creo es muy aplicable en este caso. La dedicación a la medicina se extiende a varias generaciones en su caso. Su padre Salvador Gil Vernet Catedrático de Anatomía de la Universidad de Barcelona, su tío Emili Gil Vernet catedrático de Obstericia y Ginecología en la misma Universidad.

El maestro se caso con Olga Sedó, ya fallecida, y tiene 3 hijos: Jose Maria, Alfredo y Carlos, dos de ellos son urólogos.

Nació en 1922 en años de guerra, viviendo un momento histórico memorable, el exilio de su padre por la persecución generada contra el por la II República y la experiencia del aislamiento político y financiero de nuestro País tras la guerra civil. Se licenció en Medicina por la Universidad de Barcelona en 1947.

Podemos afirmar que era un discípulo directo de su padre que fue el pionero de la urología científica. Sus investigaciones anatómicas supusieron un gran salto en el conocimiento preciso de la próstata. En conversación con su hijo Jose Maria, excepcional especialista en urología, que trabaja en la Clínica Teknon en Barcelona, me señalaba haciendo memoria de su padre, que en los orígenes trabajaba en la sala de disección de la cátedra de anatomía, entrenando la anatomía topográfica urogenital, que fue la base de su habilidad quirúrgica.

Este es el momento tal vez, mis queridos amigos académicas y académicos, de dar a conocer mi vinculación continuada con parte de la vida académica del Profesor Jose Maria Gil-Vernet Vila. Agradezco aquí el gesto de nuestro presidente saliente el Profesor Joaquín Poch y su junta directiva, por asignarme el honor de actuar bajo precepto en esta sesión necrológica que tanto nos honra. Aprovecho esta ocasión para mostrar mi reconocimiento por la fenomenal labor de gestión que han realizado.

Obtuve mi licenciatura y doctorado en el Hospital Clinic Universitario de Barcelona en 1966 en la que mi padre, miembro de esta Real Academia, era también Catedrático de Medicina Interna. En la actualidad mi hermano Laureano al que me referiré posteriormente, es el Catedrático de Cirugía de esa prestigiosa Universidad, es lo que me permite ponerle cara a lo que digo con imborrables memorias que voy a compartir.

El maestro Gil-Vernet se doctora en Madrid en 1951 y adquiere la especialidad de urología en 1956. Obtiene la plaza de jefe de servicio de urología en el Hospital Clinic en 1972, que coincide con mi desplazamiento a la Universidad de Yale para sufrir mi entrenamiento post-doctoral.

Empezaré por señalar que logró alcanzar una prodigiosa técnica quirúrgica, en la que destacaría la exquisitez en el logro de la disección de los planos anatómicos que había adquirido en la sala de prácticas de la Cátedra de Anatomía con su padre que ya he mencionado. No se contentaba señoras y señores académicos y académicas, en mejorar la técnica, sino que su aspiración era siempre cambiar radicalmente la misma.

Sus aportaciones más destacables son entre otras: las aplicables a la eliminación del cálculo renal (en 
su forma coraliforme), la corrección del reflujo versículo uretral, la aportación en el campo de las neoplasias, la autoplastia vesical con un colgante vesical postero superior, la colocistoplastia, la cirugía renal extracorpórea y la introducción de la biopsia peroperatoria en urología y andrología

Lo que le definía en el quirófano, era en boca de sus discípulos, que el detalle más insignificante era suficiente para mejorar la técnica.

Pero uno de los hechos más relevantes que le catapulta a su internacionalidad es su visionaria aportación a la historia de los trasplantes. En 1965 un año antes de que yo finalizara mi licenciatura en el Clínic en Barcelona, efectúa el primer trasplante de riñón con éxito en España que realiza con el Dr. Antonio Caralps como coordinador del equipo de trasplante. El doctor Antonio Caralps era a la sazón mi jefe de guardias en medicina interna durante mi aprendizaje / entrenamiento en el Clinic en Barcelona. No quiero extenderme pero soy consciente que sois capaces de comprender que tuvo que abrirse paso a los problemas legales, éticos y religiosos que por ser pionero tuvo que asumir y resolver con maestría.

Os podréis imaginar que en un Hospital, como era el viejo caserón de la calle Casanovas no estaba preparado para ello y constituye una hazaña de dimensiones colosales. Se inicia desde entonces y bajo su dirección el programa de trasplante renal en el Clinic. Os invito a compartir el privilegio que era para mí, estar sentado en primera línea como observador ávido de descubrir la excelencia en la práctica de la medicina. En 1978 a mi vuelta de la Universidad de Yale, disfruto de la noticia que el maestro Gil Vernet ha logrado efectuar con éxito el primer trasplante mundial de testículo humano con veinte especialistas. En 1983 con mi hermano Laureano, Catedrático de Cirugía de la Universidad de Barcelona hacen el primer trasplante de páncreas y riñón en un paciente de 32 años que sufría de diabetes tipo 1 que presentaba las complicaciones micro-macro antipáticas con insuficiencia renal terminal. La experiencia acumulada nos dice que estas primeras intervenciones en humanos siempre han tenido problemas con la supervivencia largo plazo. Este paciente mis queridos amigos/as murió 10 años mas tarde de un infarto agudo de miocardio. En palabras del profesor Laureano Fernandez-Cruz estábamos ante un cirujano excepcional y lo define como un explorador incansable, innovador y creativo.

Como grandísimo profesional ofertaba servir con su saber y habilidad quirúrgica no solo en el Hospital Clinic de Barcelona sino en la clínica San Jose en donde recibía de todos los rincones del país a los enfermos. Entre ellos a las personas más relevantes del mundo de la cultura, financiera y política de nuestro País. Su Majestad el Rey Juan Carlos fue también su paciente y amigo. Le llevó a ser el único urólogo español que aparece citado en la Enciclopedia Britanica además de la Wikipedia en el momento actual.
Entre los múltiples reconocimientos distinguiría la que obtuvo de la Asociación Europea de Urólogos innovadores en 2016, the Distinguished Career Award of the Société International d'Urologie in 2009, y la medalla Francisco Díaz de la Asociación Española de Urología in 2002.

Que les puedo comentar en este recuerdo apasionado, que ustedes no conozcan de su faceta docente. La última vez que el vi, fue en este recinto, dando una de sus conferencias magistrales que hemos tenido el placer de disfrutar. Hasta el último momento no dudaba en sus 90s coger el AVE para participar activamente en las sesiones científicas de nuestra Real Academia Nacional de Medicina de España.

Tenía la virtud, habilidad innata o heredada de comunicarse fácilmente y además mostraba su voluntad de hacerlo. En el quirófano, recogiendo palabras de sus discípulos la resumiría "en el que siempre que le veías operar te ibas a casa con la sensación de que habías aprendido algo". Era repito un gran comunicador y sus contribuciones en el aula de la Facultad y en sus conferencias eran extraordinariamente apreciadas. Lo que creo caracterizó su docencia fue que nunca trató de convencer, de persuadir, de halagar a sus oyentes. Exponía sus ideas; eso era todo.

En sus cursos internacionales de urología aplicaban la tecnología más avanzada en la comunicación como era retransmitir directamente al auditorio del Palau de Congresos de la Ciudad Condal a más de 1000 asistentes, sus intervenciones en directo desde quirófano del Clinic. Contribuyó por lo tanto al método de enseñanza digital o telemática tan en boga en el momento actual. Afortunadamente un número apreciable de sus intervenciones fueron filmadas con un objetivo educativo. Gracias a la iniciativa de su hijo Jose Maria Gil-Vernet Sedó disponemos de estas joyas, que nos permiten apreciar la precisión de su técnica quirúrgica. Alrededor tenía una pléyade de alumnos médicos que procedían de diferentes países dispuestos a aprender la urología científica e innovadora que ejercía con maestría en el Clinic de Barcelona. El maestro Gil-Vernet conquistó a su época

Su impacto internacional se consolidó con amistades duraderas, con el Prof. Jean B. DeKernion, en UCLA. Con él conoció y compartió conocimientos con los Dres. Joseph Kaufman y el Dr. Ruben Gittes quien solía acudir, como profesores invitados, a los Cursos Internacionales de Urología de Barcelona. En 1967 fue invitado por el Prof. Dr. Willard Googwin, jefe de Servicio de Urología de la UCLA, donde operó a varios pacientes, convirtiéndose en el único urólogo español (sin el Board) que ha podido operar en USA. Me gustaría destacar que los profesores Googwin, Kaufman y Ruben Gates han sido gigantes de la urología mundial. En esta iconografía que os muestro se documenta su relación internacional con los mejores en su especialidad En Europa me gustaría destacar su relación con El Prof. T. Allen (urólogo pediatra) y con los Dr. A. Badenoch y John Blandy del reino unido que le invitaron a operar a Londres. 
También colaboró con los urólogos franceses Prof. A. Steg y Prof. L. Boccon-Gibod, con los belgas C. Schulmann y H. van Poppel, con el alemán Prof. Hohenfellner, con el venezolano Prof. J. Regetti y con el italiano Prof. Selvaggi. El ruso Prof. Lopatkin que también lo invitó a operar a Moscú. Tenía especial amistad con el urólogo Belga W. Gregoir que compartía con el hobby de la caza.

Alrededor de este profesional inigualable se creó la necesidad de incorporarle a la vida Universitaria al máximo nivel. Por ello fue nombrado Catedrático Extraordinario por el rector Estapé en 1975.

Ha sido un hombre bravo, y caballeroso, en un principio alegre de espíritu, apasionadamente aficionado a su urología, a la caza y amigo del pueblo. La villa de Vandellos le eligió como hijo predilecto. El trabajo constituye para Gil-Vernet su placer y solo en este constante empleo de energía tiene conocimiento de su vitalidad con gozo. Me gustaría para terminar descubrir ante ustedes el otro gusto de Jose Maria Gil Vernet, que es la caza, que no le hace perder el otro que como ya he mencionado era el trabajo.

Les presento una serie de momentos que ilustra esta pasión o hobby que practicaba con asiduidad. No sorprendo a nadie si afirma que la caza ha sido un tema artístico muy tratado a lo largo de la historia.

He aprendido a admirar a los cazadores. Imaginamos la caza en soledad que en algunos la tiene pero muy al contrario la mayoría de las veces, requiere una tribu que te acompaña en esta ancestral práctica deportiva. Su práctica tiene muy en cuenta, el equilibrio medio ambiental con impacto económico y social. De muchacho y durante los años de la guerra civil el joven Gil-Vernet cazaba en la sierra de Vandellós conejos y perdices y pescaba en la playa de Cadaloques. En la caza menor que era la que con mayor frecuencia practicaba juegan un papel determinante los perros de caza. De ahí que os muestre a sus mejores amigos de los que no se separaba en esta última etapa de su vida ni para dormir (Frida, Tula, Toy, Crisli, Trasto, Drac, Duna, Prosta, Xana..). Eran ellos su compañía inseparable hasta que cumplió los 96 años, acompañándole con su hijo al campo. Los vínculos entre cazador y su can son realmente estrechos e inquebrantables. Es el compañero inseparable de todas sus actividades, su colaborador, su nariz su oído y sobretodo su instinto. La compenetración entre ambos es imposible de superar, se convierte en uno más de la familia

Pero su espíritu creativo lo aplicó también a la cinegética. De su hijo Jose Maria aprendí que ya era capaz de diseñar, en su adolescencia, originales trampas para capturar pinzones o mejorar la reutilización del pistón en el cartucho.

He mencionando a la Familia en diferentes ocasiones a lo largo de mi charla. Quiero dejar constancia que ha sido un gran padre de familia como modelo a seguir.
Este ser humano especial, siguió con su actividad científica y quirúrgica hasta mucho después de su jubilación. Su última intervención fue una pielolitotomía por litiasis coraliforme y la llevó a cabo en el Hospital Virgen Macarena de Sevilla, aunque, según sus palabras: "encontró algo cansados a sus ayudantes".

Siempre he defendido en mi lucha contra las enfermedades crónicas, que no son estas el problema. El único problema es la muerte que se convierte en una anécdota que de momento asumimos con resignación.

Soy consciente que ante esta figura gigantesca, tal vez por mis limitaciones, he hecho un retrato de poco valor. Nietzsche asertaba que todo genio, y Jose Maria lo era, lleva una máscara. Yo no he llegado a descubrirla pero coincidirán conmigo, que su endemoniada capacidad de trabajo, su afán de saber y la atracción a una profesión, la urología, podrían constituir parte de los aderezos de la misma.

El profesor Jose Maria Gil-Vernet ha llegado a la ribera opuesta, ha cruzado el rio de la vida y en su última mirada imagino, contempla los hombres y mujeres en la ribera abandonada. Creo sinceramente que expresa la despedida de una generación. Siguiendo los dictados de mi conciencia he resumido ante ustedes mi versión de los hechos. No se puede valorar una fuerza si no se conoce su resistencia ni una acción si no se conocen sus sacrificios. En esta comedia de la vida las personas tienen destinos y deparó para el maestro Gil-Vernet el más grande que hoy festejamos en su memoria.

Es fácil ser agradecido. El agradecer es un acto difícil pues requiere una tranquilidad del corazón que yo no tengo. Hay algo que me inquieta sobremanera y es la de saber si realmente merezco el honor que la Academia acaba de dispensarme, con su preceptivo incondicional agradecimiento al Maestro Gil-Vernet, que nos deja una huella imborrable y que siempre será nuestro.

\section{DECLARACIÓN DE TRANSPARENCIA}

El autor/a de este artículo declara no tener ningún tipo de conflicto de intereses respecto a lo expuesto en el presente trabajo.

Si desea citar nuestro artículo:

Fernández-Cruz Pérez A. Sesión necrológica en memoria del Prof. José María Gil Vernet. An RANM. 2021;138(01).supl01: 25-27. D0I: 10.32440/ar.2021.138.01.supl01.art06 